\title{
Nutrient concentrations affect the antimicrobial resistance profiles of cattle manures
}

\author{
Vijay Laxmi Shrivas ${ }^{1,2} \cdot$ Anil Kumar Choudhary ${ }^{3,4} \cdot$ Puttaswamy Hariprasad $^{2} \cdot$ Shilpi Sharma $^{1}$
}

Received: 6 July 2021 / Accepted: 20 September 2021 / Published online: 10 November 2021

(C) The Author(s), under exclusive licence to Springer-Verlag GmbH Germany, part of Springer Nature 2021

\begin{abstract}
Antimicrobial resistance (AMR) in cattle is widespread because of the increased use of antibiotics to combat microbial diseases and enhance milk production. The cattle excreta released into the environment can be a potent source of contamination in spreading antibiotic resistance, especially upon its application in agriculture. However, the correlation of AMR profile of manure with other physico-chemical parameters is limited. Therefore, the study aimed to generate AMR profiles for manure samples collected from 25 different sites of two agriculturally important states in India, Madhya Pradesh and Uttar Pradesh. Samples were tested for physico-chemical parameters, viz., electrical conductivity, $\mathrm{pH}$, total nitrogen $(\mathrm{N})$, total phosphorus $(\mathrm{P})$, and total potassium (K). Bacterial community analysis was done by culture-dependent and culture-independent methods. The influence of feeding practices, nutrient concentration, and bacterial abundance on antibiotic resistance profiles was observed in collected manure samples. Manures of intensive feeding animals harbored highly resistant profiles of bacteria as compared to natural grazing cattle.
\end{abstract}

Keywords Antimicrobial resistance $\cdot$ Animal manure $\cdot$ Bacterial community $\cdot$ Environment $\cdot$ Nutrient concentration

\section{Introduction}

According to the World Health Organization, AMR is considered one of the 10 major health threats globally in 2019 (WHO 2019). Antibiotics are used to combat various microbial infections in both humans and animals. The current COVID-19 pandemic has further deepened the global implications for antimicrobial resistance through the unintended proliferation of AMR (Murray 2020; Rawson et al. 2020; Lai et al. 2021).

Responsible Editor: Diane Purchase

Shilpi Sharma

shilpi@dbeb.iitd.ac.in

1 Department of Biochemical Engineering and Biotechnology, Indian Institute of Technology Delhi, Hauz Khas, New Delhi 110016, India

2 Centre for Rural Development and Technology, Indian Institute of Technology Delhi, Hauz Khas, New Delhi 110016, India

3 Division of Agronomy, ICAR-Indian Agricultural Research Institute, New Delhi 110012, India

4 Present address: ICAR-Central Potato Research Institute, Shimla, Himachal Pradesh 171001, India
There are several factors contributing to this, one of which is the high rate of antimicrobials administered to COVID-19 patients who have a moderate to low rate of secondary or co-infection(Lai et al. 2021). In a recent report, a significant increase in multidrug-resistant organisms (MDROs), Klebsiella pneumoniae-producing extended-spectrum lactamase (ESBL), carbapenem-resistantKlebsiella pneumoniae, Acinetobacter baumannii, methicillinresistantStaphylococcus aureus (MRSA), pan-echinocandinresistantCandida glabrata, and multi-triazoleresistantAspergillus fumigatus was observed in response to the pandemic (Lai et al. 2021).

The incidence of AMR in livestock, which is generally caused due to the high dosage of antibiotics to combat diseases, increased production of milk and meat, and for improved performance of cattle is threatening (Jayarao et al. 2019). The annual intake of total antibiotics in livestock farming is estimated at around $14.8 \mathrm{~g}$ per $\mathrm{kg}$ for chicken, $17.2 \mathrm{~g}$ per $\mathrm{kg}$ for pig, and $4.5 \mathrm{~g}$ per $\mathrm{kg}$ for cattle (van Boeckel et al. 2015). The antimicrobials used in animal feeding operations are mostly water-soluble. They are not completely absorbed by the animals. A significant amount of antibiotics is excreted by animals in manure and urine (Manyi-Loh et al. 2018; Quaik 
et al. 2020). The rate and the amount of antibiotics released into the environment have been reported to be dependent on the type of antibiotic, on the dosage administered, and on the animal species and its age (Zhao et al. 2010). The excreta of the livestock can serve as a direct source of the spread of AMR in the environment (Wichmann et al. 2014).

Development of resistance due to mutation and transfer of resistance genes (horizontal gene transfer, mobile genetic elements), through plasmids, phages, transposons, or integron gene cassettes under the selection pressure of antimicrobials, is a common phenomenon (Woodford and Ellington 2007; Fondi and Fani 2010; Checcucci et al. 2020). These mechanisms of transfer of antibiotic resistance contribute significantly to AMR diffusion in the livestock. Overuse of antibiotics in the production of livestock is generally thought to be a source of AMR in the animal excreta. However, animals raised without antibiotic supplementation (natural grazers) have also shown a large incidence of antibiotic (cefotaxime)-resistant bacteria (Markland et al. 2019). High nutrient concentration in manure supports microbial load (Lima et al. 2020). Subsequently, in the presence of antimicrobials in the manure, horizontal gene transfer is triggered (Blau et al. 2018). Thus, these reports suggest that nutrients present in animal excreta can exhibit an important effect on antimicrobial resistance profiles of manure from livestock.

India has the highest livestock worldwide of $\sim 535.78$ million, with 71.6 cattle per sq. km of land (Global livestock populations 2020). In a country like India, which has also become the highest antibiotic consumer in recent years (6.3 billion defined daily doses) (Klein et al. 2021; Mutua et al. 2020), limited reports related to AMR in livestock increase the concern to a great extent. Considering the above situation, it becomes pertinent to understand the pattern of antibiotic resistance in livestock manure and its correlation, if any, with the nutrient concentration of the manure. Hence, the current work focuses on the surveillance of antibiotic resistance profiles in cattle manure samples, collected across 25 different geographical locations in Northern and Central India (Bundelkhand region). This region spreads between seven districts of Uttar Pradesh and six districts of Madhya Pradesh, having a high density of cattle ( 71 animal per sq. km of land) (Ram 2015). Cattle in Bundelkhand area are majorly dependent on crop residues and green fodder for their survival. In Bundelkhand, a notable feeding exercise, commonly known as "Anna Pratha," is followed where cattle are left outside for grazing purposes, which in turn helps in the maintenance of soil health and its fertility as livestock feeds on the crop residues (Mishra et al. 2010). We hypothesized that animal feeding practices contribute to the nutrient concentration and antibiotic resistance in cattle manure.

\section{Materials and methods}

1) Sampling and characterization of manure samples

Cattle manure samples were collected in duplicate from 25 different geographical locations in Northern and Central India (Bundelkhand region) (Supplementary Table 1, Supplementary Figure 1). Out of the 50 manure samples thus collected, 18 samples were from intensive farming sites and 32 were from natural grazing sites. To gain an in-depth understanding of the pattern of antibiotic resistance in cattle manure, and its correlation, if any, with various physico-chemical and biological characteristics of manure, both culture-dependent and cultureindependent approaches were adopted. Properties, viz., electrical conductivity (EC), $\mathrm{pH}$, total nitrogen $(\mathrm{N})$, total phosphorus $(\mathrm{P})$, and total potassium $(\mathrm{K})$, of the manure samples were analyzed using the standard methods (Moore 1968; Rana et al. 2014; Wuenscher et al. 2015). To target the total bacterial abundance, DNA was extracted from the manure samples using FastPrep-24 ${ }^{\mathrm{TM}}$ bead beater (MP Biomedicals, USA) for bead homogenization and lysis, and cetyl trimethylammonium bromide (CTAB) was used as extraction buffer (Sharma et al. 2012). The V3-V4 hypervariable region of the $16 \mathrm{~S}$ rRNA gene was used as a marker for quantification by qPCR using CFX96 ${ }^{\mathrm{TM}}$ Real-Time PCR C1000 Touch Thermal Cycler (Bio-Rad, Hercules, CA, USA) (López-Gutiérrez et al. 2004). All experimental analyses were performed in triplicates. One-way analysis of variance (ANOVA) was performed with SPSS statistical system (SPSS 20.0 for windows) to determine significant changes in the attributes between the manure samples from different locations. For a comparison between the values for the 50 locations, multiple Tukey's HSD was performed at a significance level of $P<0.05$ (Little and Hills 1978).

\section{2) Antimicrobial resistance profiling of manure samples}

For profiling of antibiotic resistance of manure samples, eight antibiotics were selected for disc diffusion assay (Davis and Stout 1971). These included ampicillin (AMP 10 mcg), azithromycin (AZM $30 \mathrm{mcg}$ ), chloramphenicol (CHL $30 \mathrm{mcg}$ ), clindamycin (CLI $2 \mathrm{mcg}$ ), doxycycline (DOX 30 $\mathrm{mcg}$ ), nalidixic acid (NAL $30 \mathrm{mcg}$ ), norfloxacin (NOR 30 $\mathrm{mcg}$ ), and sulfadiazine (SUL $100 \mathrm{mcg}$ ). One gram of manure sample was serially diluted, followed by plating of $100 \mu \mathrm{L}$ of the final dilution on nutrient agar medium containing fluconazole (50 $\mathrm{mg} \mathrm{L}^{-1}$ ) as antifungal agent (Kunova and Piecková 2002). Antibiotic discs were placed on plates and then incubated for 2 days at $30^{\circ} \mathrm{C}$. Subsequently, the plates were examined for the zone of inhibition, to determine the antibiotic sensitivity of the bacterial load. 


\section{Results and discussion}

Manure samples were observed to be rich in nutrients with varying concentrations across the sampling locations (Supplementary Table 2). In the manure samples, the total nitrogen, phosphorus, and potassium contents ranged between 1.5-36, 2-95, and 5.2-20 $\mathrm{g} \mathrm{kg}^{-1}$, respectively. Several studies around the globe have reported the application of manure for building nutrient (N, P, K) status in soil (Schlegel et al. 2017; Ozlu et al. 2019; Chatzistathis et al. 2020). Apart from the quantification of major nutrients, $\mathrm{pH}$ and $\mathrm{EC}$ were measured as both play crucial roles in affecting the nutrient concentrations and microbial activity (Azeez and van Averbeke 2012; Hill et al. 2021). The $\mathrm{pH}$ of the manure samples varied from acidic to basic (5.79-9.05), while electrical conductivity was found to be in the range of $0.01-0.06 \mathrm{dS} \mathrm{m}^{-1}$. Distinct differences have been reported in the $\mathrm{pH}$ and $\mathrm{EC}$ values upon comparison of different types of manure, viz., poultry, cattle, and goat, and it is believed to reflect upon the differences in animal feeding practices (Azeez and van Averbeke 2012). Also, a strong connection has been found among the type of nutrients present and bacterial community dynamics by Zhang et al. (2017). 16S rRNA gene copies in the manure samples ranged from $5.58 \times 10^{4}$ to $2.04 \times 10^{11}$ gene copy number per gram dry manure (Supplementary Table 2 ). Pearson correlation $(r)$ between bacterial abundance and the nutrient concentrations revealed significant correlation with nitrogen $(r=0.48$, $P=0.01)$, phosphorus $(r=0.33, P=0.05)$, and potassium $(r=0.32, P=0.05)$ (Table 1$)$. The $\mathrm{pH}(r=0.04)$ of manure samples did not show any significant correlation with bacterial abundance, whereas a significant negative relationship was seen with EC ( $r=-0.31, P=0.05)$.

The result of the disc diffusion assay showed diverse resistance profiles of the bacterial community present in manure samples (Figure 1, Table 2). Most of the manure samples exhibited resistance against multiple antibiotics. Out of the 50 samples, only nine samples, viz., S1, S7, S18, S19, S23, S24, S26, S34, and S36, were found to be resistant against only a single antibiotic, viz., sulfadiazine, clindamycin, nalidixic acid, ampicillin, and norfloxacin. Cultivable bacteria from manure samples showed the maximum percentage of resistance against clindamycin (24\%) followed by nalidixic acid (22\%), ampicillin (14\%), sulfadiazine (13\%), norfloxacin (10\%), doxycycline (9\%), chloramphenicol $(5 \%)$, and azithromycin (3\%).

Clindamycin belongs to the macrolide group of antibiotics and is one of the most commonly administered as veterinary medicines (Wang et al. 2016). A spike of clindamycinresistant coliforms was reported in the soil after the application of manure (Wind et al. 2018). Clindamycin was observed to enrich the culturable Proteobacteria on the surface of tomatoes (Lee et al. 2016). Nalidixic acid belongs to the quinolone group of antibiotics and has been popularly used in veterinary consumption for treating intestinal infections in livestock (Boothe 2015). Quinolones have been reported to be persistent in manure with dissipation time ( $\mathrm{DT}_{90}$ ) ranging from 100 to 5800 days (Berendsen et al. 2018). In a recent study, nalidixic acid-resistant $E$. coli was found in beef cattle farmyard manure, which contributed to $1.2 \%$ of the total resistant isolates (Huygens et al. 2021). In the current study, the cultivable bacteria present in the manure samples showed significant resistance (22\%) against nalidixic acid. Out of the total AMR recorded in manure samples, ampicillin and sulfadiazine resistance contributed to $14 \%$ and $13 \%$, respectively. Sulfonamides are widely present in human and animal wastes (Adekanmbi et al. 2020; Huygens et al. 2021). A recent study reported that $75 \%$ of sulfonamide-resistant bacteria were found to be resistant to ampicillin (Adekanmbi et al. 2020), which is in accordance with the data obtained in the present study. Pearson correlation $(r)$ was drawn among profiles of antibiotic resistance bacteria (ARB), physico-chemical parameters, and bacterial abundance in the manure samples (Table 1).

AMR in manure samples showed a significant positive correlation with nitrogen and phosphorus content of the manure $(r=0.69$ and $r=0.54$, respectively, $P=0.01)$. The
Table 1 Pearson correlation matrix among physico-chemical parameters, copies of $16 \mathrm{~S}$ rRNA gene, and antibiotic resistance patterns of manure

\begin{tabular}{llllllll}
\hline Parameters & $\mathrm{N}$ & $\mathrm{P}$ & $\mathrm{K}$ & $\mathrm{pH}$ & $\mathrm{EC}$ & $\begin{array}{l}\text { 16S rRNA gene } \\
\text { copies }\end{array}$ & AMR \\
\hline $\mathrm{N}$ & 1 & $0.558^{* *}$ & $0.330^{*}$ & 0.181 & 0.185 & $0.486^{* *}$ & $0.690^{* *}$ \\
$\mathrm{P}$ & $0.558^{* *}$ & 1 & 0.225 & 0.160 & $0.358^{*}$ & $0.329^{*}$ & $0.543^{* *}$ \\
$\mathrm{~K}$ & $0.330^{*}$ & 0.225 & 1 & 0.062 & -0.080 & $0.320^{*}$ & $0.283^{*}$ \\
$\mathrm{pH}$ & 0.181 & 0.160 & 0.062 & 1 & 0.256 & 0.040 & 0.099 \\
$\mathrm{EC}$ & 0.185 & $0.358^{*}$ & -0.080 & 0.256 & 1 & $-0.312^{*}$ & -0.034 \\
Total bacterial & $0.486^{* *}$ & $0.329^{*}$ & $0.320^{*}$ & 0.040 & $-0.312^{*}$ & 1 & $0.629^{* *}$ \\
$\quad$ abundance & $0.690^{* *}$ & $0.543^{* *}$ & $0.283^{*}$ & 0.099 & -0.034 & $0.629^{* *}$ & 1 \\
ARB & & & & & & &
\end{tabular}

**Correlation is significant at the 0.01 level (2-tailed). *Correlation is significant at the 0.05 level (2-tailed). N nitrogen, $\mathrm{P}$ phosphorus, $\mathrm{K}$ potassium, EC electrical conductivity, AMR antimicrobial resistance profiles of manure 
Table 2 Profiling of antibiotic resistance in cultivable bacteria in the manure samples collected from 50 different locations

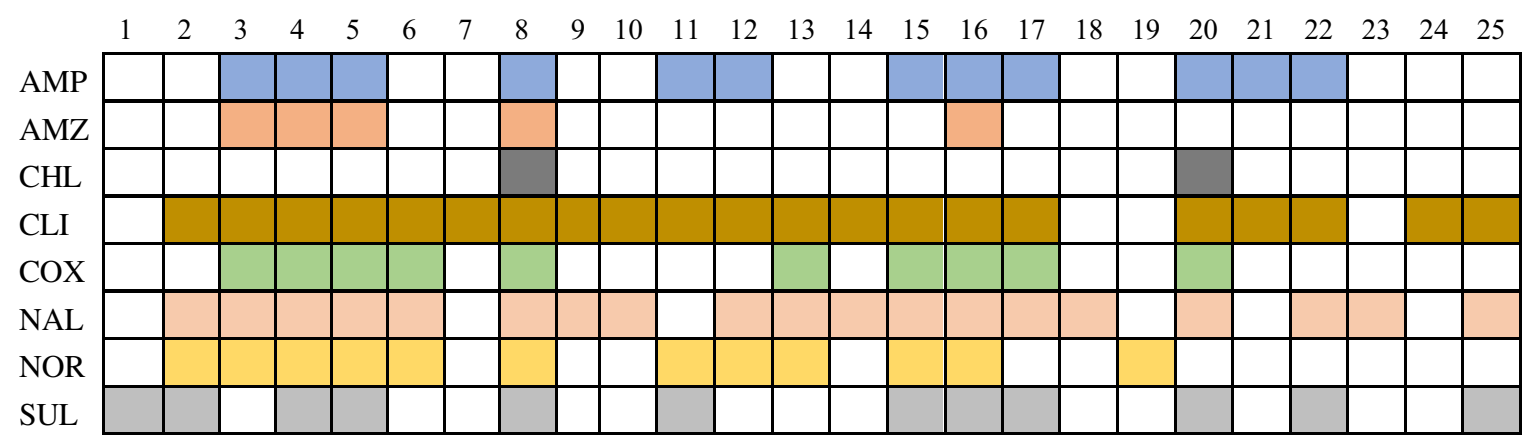

\begin{tabular}{|c|c|c|c|c|c|c|c|c|c|c|c|c|c|c|c|c|c|c|c|c|c|c|c|c|c|}
\hline & 26 & 27 & 28 & 29 & 30 & 31 & 32 & 33 & 34 & 35 & 36 & 37 & 38 & 39 & 40 & 41 & 42 & 43 & 44 & 45 & 46 & 47 & 48 & 49 & 50 \\
\hline AMP & & & & & & & & & & & & & & & & & & & & & & & & & \\
\hline AMZ & & & & & & & & & & & & & & & & & & & & & & & & & \\
\hline $\mathrm{CHL}$ & & & & & & & & & & & & & & & & & & & & & & & & & \\
\hline CLI & & & & & & & & & & & & & & & & & & & & & & & & & \\
\hline $\mathrm{COX}$ & & & & & & & & & & & & & & & & & & & & & & & & & \\
\hline NAL & & & & & & & & & & & & & & & & & & & & & & & & & \\
\hline NOR & & & & & & & & & & & & & & & & & & & & & & & & & \\
\hline SUL & & & & & & & & & & & & & & & & & & & & & & & & & \\
\hline
\end{tabular}

Colored boxes represent antibiotic resistance against the particular antibiotic. $\square$ AMP: ampicillin, $\square$ AZM: azithromycin, $\square$ CHL: chloramphenicol, CLI: clindamycin, DOX: doxycyclin€ NAL: nalidixic acic NOR: norfloxacin, a I SUL: sulfadiazine Colored boxes represent antibiotic resistance against the particular antibiotic. AMP: ampicillin, AZM: azithromycin, CHL: chloramphenicol, CLI: clindamycin, DOX: doxycycline, NAL: nalidixic acid, NOR: norfloxacin, and SUL: sulfadiazine

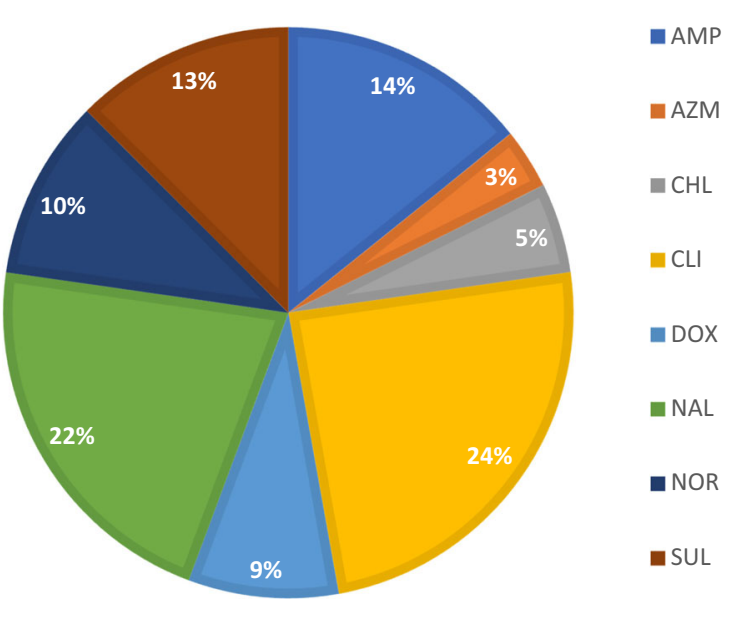

Fig. 1 Percentage distribution of antibiotic resistance in cultivable bacteria present in manure. AMP ampicillin, AZM azithromycin, CHL chloramphenicol, CLI clindamycin, DOX doxycycline, NAL nalidixic acid, NOR norfloxacin, SUL sulfadiazine correlation coefficient between AMR profiles of manure and potassium was $r=0.28(P=0.05)$. The $\mathrm{pH}$ profiles of manure did not correlate with AMR (with $r=0.09$ ), while negative relationship was seen in the case of electrical conductivity $(\mathrm{r}=-0.034)$. $\mathrm{pH}$ of manure is dependent on the integral composition and nature of the supplements given to livestock (Lin et al. 2020). Lin et al. (2020) reported the effect of acidic $\mathrm{pH}$ in the reduction of sulfonamide-resistant bacteria. However, the fate of AMR in manure was unclear. In the current study, no such significant correlation was found between antibiotic resistance and the $\mathrm{pH}$ of the manure samples. The $16 \mathrm{~S}$ rRNA gene copy number in the manure samples showed a significant positive correlation with antibiotic resistance profiles of manure $(r=0.63, P=0.01)$. However, in the study, the antibiotic resistance profiles generated using cultivation-dependent approach represents only a small fraction of the total bacterial community that are culturable (Hofer 2018). Positive correlations have been reported between the abundance of 16S rRNA gene copies and antibiotic resistance in manure-amended soil using both cultivable and uncultivable methods (UdikovicKolic et al. 2014; McKinney et al. 2018). Moreover, manure treatment has been found to specifically enhance the $b l a_{\mathrm{CEP}-04}$ gene copies, as estimated by qPCR. Manure has the potential 


\section{Component Plot in Rotated Space}

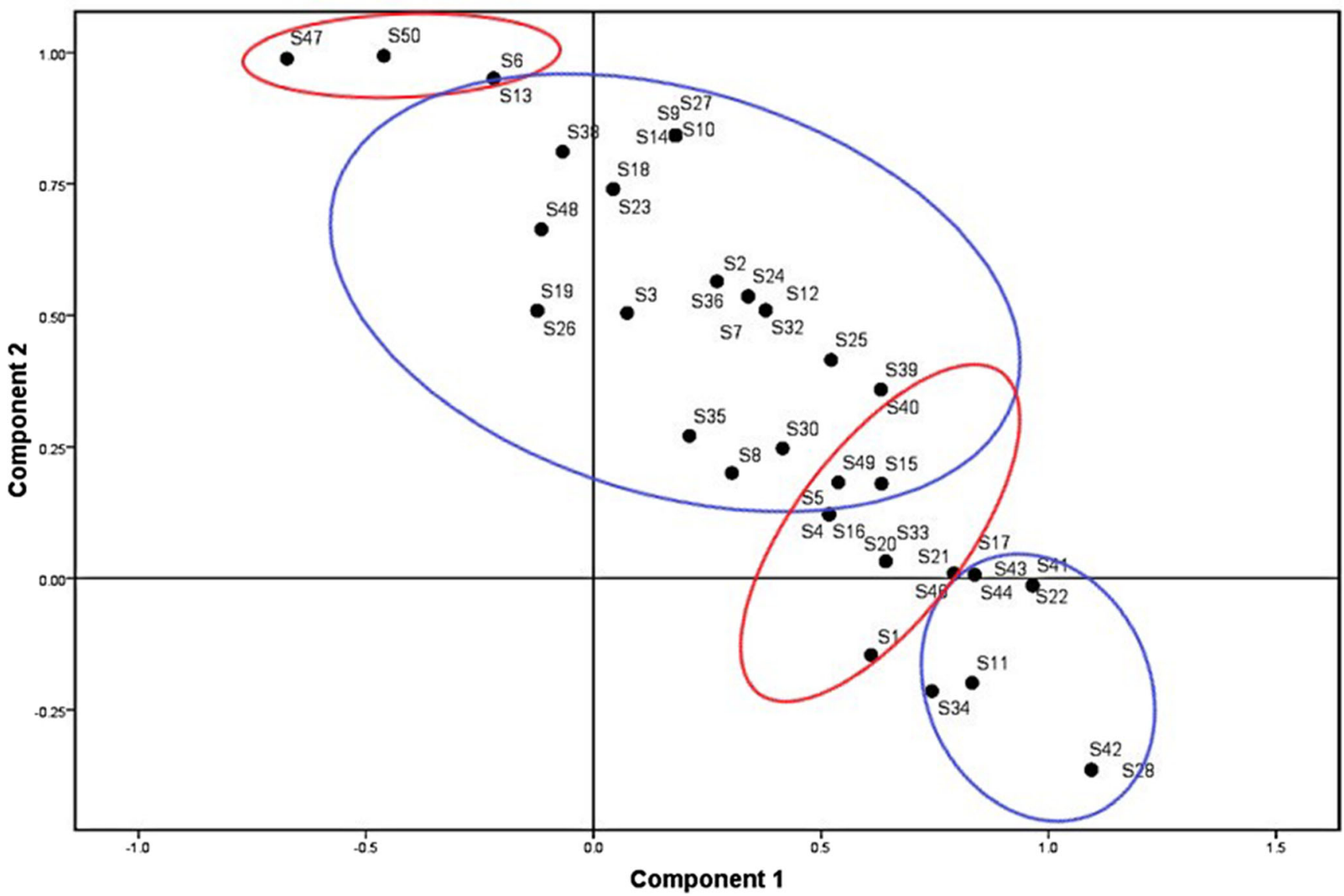

Fig. 2 Principal component analysis of the antibiotic resistance profiles of manure samples. S1-S50 refers to ID of samples collected from different coordinates. Blue ring refers to the manure samples collected from

natural grazing animals, whereas red ring indicates cattle manure samples collected from intensive farming

for the emergence and proliferation of antibiotic resistance in native microbiota (Yuan et al. 2019; Chen et al. 2016; Zhang et al. 2019). Udikovic-Kolic et al. (2014) described the presence of Pseudomonas and Janthinobacterium spp. as a major component of manure microbiota containing $\beta$-lactamase genes. Janthinobacterium belongs to the order Burkholderiales that uses ammonium as the sole nitrogen source (Gillis and Logan 2015). This is in accordance with the present study as positive correlations were observed between nutrients present in the manure and the population of antibiotic-resistant bacteria in the manure.

Principal component analysis of antibiotic resistance profiles of manure reflected clustering based on the cattle feeding practices (Figure 2). Samples collected from natural grazing animals were clustered together, whereas those from intensive farming zones were grouped separately, though some outliers clustered differently as they shared similar antibiotic resistance profiles. Similar correlation was reported in a study where swine under artificial feeding resulted in higher

antibiotic residues in manure as compared to natural feed (Pan et al. 2011).

\section{Conclusions}

The present study attempted to comprehend the patterns of antimicrobial resistance prevalent in manure samples collected from different geographical locations of north and central India. A positive correlation was observed between the AMR profiles and nutrient concentrations of manure samples. A strong impact of feeding strategies was also evident on AMR profiles. This outcome serves as a basis for carrying out future studies in surveillance and in policy-making for the use of important veterinary antibiotics. However, the study was conducted with cattle manure collected from selected regions of India. Further studies are needed to comprehend the antibiotic footprints in the agricultural and veterinary sectors across different regions of the country and beyond. 
Supplementary Information The online version contains supplementary material available at https://doi.org/10.1007/s11356-021-16700-6.

Author contribution VLS performed the experiments and wrote the first draft of the manuscript, AKC procured the samples, VLS and PH analyzed the data, AKC and SS procured the funding and designed the experiments, and SS and PH supervised the study; all authors reviewed and approved the manuscript.

Funding This research was supported by the Department of Biotechnology, Government of India (BT/PR27680/BCE/8/1434/2018).

Data availability All data generated or analyzed during this study are included in this published article [and its supplementary information files].

\section{Declarations}

Ethics approval and consent to participate Not applicable

Consent for publication Not applicable

Competing interests The authors declare no competing interests.

\section{References}

Adekanmbi AO, Adejoba AT, Banjo OA, Saki M (2020) Detection of sul1 and sul2 genes in sulfonamide-resistant bacteria (SRB) from sewage, aquaculture sources, animal wastes and hospital wastewater in south-west Nigeria. Gene Rep 20:100742

Azeez JO, van Averbeke W (2012) Dynamics of soil pH and electrical conductivity with the application of three animal manures. Commun Soil Sci Plan 43:865-874

Berendsen BJA, Lahr J, Nibbeling C, Jansen LJM, Bongers IEA, Wipfler EL, van de Schans MGM (2018) The persistence of a broad range of antibiotics during calve, pig and broiler manure storage. Chemosphere 204:267-276

Blau K, Bettermann A, Jechalke S, Fornefeld E, Vanrobaeys Y, Stalder T et al (2018) The transferable resistome of produce. mBio 9:e01300 e01318

Boothe DM (2015) Quinolones, including fluoroquinolones https://www. msdvetmanual.com/pharmacology/antibacterial-agents/ quinolones,-including-fluoroquinolones?query=Quinolones, $\%$ 20including\%20fluoroquinolone

Chatzistathis T, Papadakis IE, Papaioannou A, Chatzissavvidis C, Giannakoula A (2020) Comparative study effects between manure application and a controlled-release fertilizer on the growth, nutrient uptake, photosystem II activity and photosynthetic rate of Olea europaea L.(cv.'Koroneiki'). Sci Hortic 264:109176

Checcucci A, Trevisi P, Luise D, Modesto M, Blasioli S, Braschi I, Mattarelli P (2020) Exploring the animal waste resistome: the spread of antimicrobial resistance genes through the use of livestock manure. Front Microbiol 11:1416

Chen Q, An X, Li H, Su J, Ma Y, Zhu YG (2016)Long-term field application of sewage sludge increases the abundance of antibiotic resistance genes in soil. Environ Int 92:1-10

Davis WW, Stout TR (1971) Disc plate method of microbiological antibiotic assay: I. Factors influencing variability and error. Appl Microbiol 22:659-665
Fondi M, Fani R (2010) The horizontal flow of the plasmid resistome: clues from inter-generic similarity networks. Environ Microbiol 12: 3228-3242

Gillis M, Logan NA (2015)Janthinobacterium. Bergey's Manual of Systematics of Archaea and Bacteria 1-12.

Global livestock populations 2020. www.livestockdata.org/data-object/ global-livestock-populations

Hill D, Morra MJ, Stalder T, Jechalke S, Top E, Pollard AT, Popova I (2021) Dairy manure as a potential source of crop nutrients and environmental contaminants. J Environ Sci 100:117-130

Hofer U (2018) The majority is uncultured. Nat Rev Microbiol 16:716717

Huygens J, Daeseleire E, Mahillon J, van Elst D, Decrop J, Meirlaen J, Dewulf J, Heyndrickx M, Rasschaert G (2021) Presence of antibiotic residues and antibiotic resistant bacteria in cattle manure intended for fertilization of agricultural fields: a one health perspective. Antibiotics 10:410

Jayarao B, Almeida R, Oliver SP (2019) Antimicrobial resistance on dairy farms. Foodborne Pathog Dis 16:1-4

Klein EY, Milkowska-Shibata M, Tseng KK, Sharland M, Gandra S, Pulcini C, Laxminarayan R (2021) Assessment of WHO antibiotic consumption and access targets in 76 countries, 2000-15: an analysis of pharmaceutical sales data. Lancet Infect Dis 21:107-115

Kunova Z, Piecková E (2002) Isolation of fluconazole-tolerant micromycetes onto different cultivation media. Folia Microbiol 47: $113-117$

Lai CC, Chen SY, Ko WC, Hsueh PR (2021) Increased antimicrobial resistance during the COVID-19 pandemic. Int J Antimicrob Agents 106324.

Lee SA, Park J, Chu B, Kim JM, Joa JH, Sang MK (2016) Comparative analysis of bacterial diversity in the rhizosphere of tomato by culture-dependent and -independent approaches. J Microbiol 54: $823-831$

Lima T, Domingues S, Da Silva GJ (2020) Manure as a potential hotspot for antibiotic resistance dissemination by horizontal gene transfer events. Vet Sci 7:110

Lin H, Sun W, Yu Q, Ma J (2020) Acidic conditions enhance the removal of sulfonamide antibiotics and antibiotic resistance determinants in swine manure. Environ Pollut 263:114439

Little TM, Hills FJ (1978) Agricultural experimentation: design and analysis. Wiley, New York, pp 84-85

López-Gutiérrez JC, Henry S, Hallet S, Martin-Laurent F, Catroux G, Philippot L (2004) Quantification of a novel group of nitratereducing bacteria in the environment by real-time PCR. J Microbiol Methods 57:399-407

Manyi-Loh C, Mamphweli S, Meyer E, Okoh A (2018) Antibiotic use in agriculture and its consequential resistance in environmental sources: potential public health implications. Molecules 23:795

Markland S, Weppelmann TA, Ma Z, Lee S, Mir RA, Teng L, Ginn A, Lee C, Ukhanova M, Galindo S, Carr C (2019) High prevalence of cefotaxime resistant bacteria in grazing beef cattle: a cross sectional study. Front Microbiol 10:176

McKinney CW, Dungan RS, Moore A, Leytem AB (2018) Occurrence and abundance of antibiotic resistance genes in agricultural soil receiving dairy manure. FEMS Microbiol Ecol 94:fiy010

Mishra S, Sharma S, Vasudevan P, Bhatt RK, Pandey S, Singh M, Pandey SN et al (2010) Livestock feeding and traditional healthcare practices in Bundelkhand region of Central India. Indian J Tradit Knowl 9:333-337

Moore EW (1968) Determination of $\mathrm{pH}$ by the glass electrode: $\mathrm{pH}$ meter calibration for gastric analysis. Gastroenterology 54:501-507

Murray AK (2020) The novel coronavirus COVID-19 outbreak: global implications for antimicrobial resistance. Front Microbiol 11:1020 
Mutua F, Sharma G, Grace D, Bandyopadhyay S, Shome B, Lindahl J (2020) A review of animal health and drug use practices in India, and their possible link to antimicrobial resistance. Antimicrob Resist Infect Control 9:1-13

Pan X, Qiang Z, Ben W, Chen M (2011) Residual veterinary antibiotics in swine manure from concentrated animal feeding operations in Shandong Province, China. Chemosphere 84:695-700

Ozlu E, Sandhu SS, Kumar S, Arriaga FJ (2019) Soil health indicators impacted by long-term cattle manure and inorganic fertilizer application in a corn-soybean rotation of South Dakota. Sci Rep 9:1-11

Quaik S, Embrandiri A, Ravindran B, Hossain K, Al-Dhabi NA, Arasu MV, Ignacimuthu S, Ismail N (2020) Veterinary antibiotics in animal manure and manure laden soil: scenario and challenges in Asian countries. J King Saud Univ Sci 32:1300-1305

Ram D (2015) Effect of Anna Pratha practice in livestock management in Bundelkhand region [https://krishikosh.egranth.ac.in/handle/1/ 5810061509].

Rana KS, Choudhary AK, Sepat S, Bana RS, Dass A (2014) Methodological and analytical agronomy. Post Graduate School, ICAR-Indian Agricultural Research Institute, New Delhi, India. pp 276

Rawson TM, Moore LS, Castro-Sanchez E, Charani E, Davies F, Satta G, Holmes AH et al (2020)COVID-19 and the potential long-term impact on antimicrobial resistance. J Antimicrob Chemother 75:16811684

Schlegel AJ, Assefa Y, Bond HD, Haag LA, Stone LR (2017) Changes in soil nutrients after 10 years of cattle manure and swine effluent application. Soil Tillage Res 172:48-58

Sharma S, Mehta R, Gupta R, Schloter M (2012) Improved protocol for the extraction of bacterial mRNA from soils. J Microbiol Methods 91:62-64

Udikovic-Kolic N, Wichmann F, Broderick NA, Handelsman J (2014) Bloom of resident antibiotic-resistant bacteria in soil following manure fertilization. Proc Natl Acad Sci U S A 111:15202-15207 van Boeckel TP, Brower C, Gilbert M, Grenfell BT, Levin SA, Robinson TP, Teillant A, Laxminarayan R (2015) Global trends in antimicrobial use in food animals. Proc Natl Acad Sci U S A 112:5649-5654

Wang N, Guo X, Yan Z, Wang W, Chen B, Ge F, Ye B (2016) A comprehensive analysis on spread and distribution characteristic of antibiotic resistance genes in livestock farms of Southeastern China. PLoS One 11:e0156889

Wichmann F, Udikovic-Kolic N, Andrew S, Handelsman J (2014) Diverse antibiotic resistance genes in dairy cow manure. mBio 5:2.

Wind L, Krometis LA, Hession WC, Chen C, Du P, Jacobs K et al (2018) Fate of pirlimycin and antibiotic-resistant fecal coliforms in field plots amended with dairy manure or compost during vegetable cultivation. J Environ Qual 47:436-444

Woodford N, Ellington MJ (2007) The emergence of antibiotic resistance by mutation. Clin Microbiol Infect 13:5-18

Wuenscher R, Unterfrauner H, Peticzka R, Zehetner F (2015) A comparison of 14 soil phosphorus extraction methods applied to 50 agricultural soils from Central Europe. Plant Soil Environ 61:86-96

Yuan K, Yu K, Yang R, Zhang Q, Yang Y, Chen E, Lin L, Luan T, Chen W, Chen B (2019) Metagenomic characterization of antibiotic resistance genes in Antarctic soils. Ecotoxicol Environ Saf 176:300-308

Zhang YJ, Hu HW, Chen QL, Singh BK, Yan H, Chen D, He JZ (2019) Transfer of antibiotic resistance from manure-amended soils to vegetable microbiomes. Environ Int 130:104912

Zhang Y, Shen H, He X, Thomas BW, Lupwayi NZ, Hao X, Thomas MC, Shi X (2017) Fertilization shapes bacterial community structure by alteration of soil $\mathrm{pH}$. Front Microbiol 8:1325

Zhao L, Dong YH, Wang H (2010) Residues of veterinary antibiotics in manures from feedlot livestock in eight provinces of China. Sci Total Environ 408:1069-1075

Publisher's note Springer Nature remains neutral with regard to jurisdictional claims in published maps and institutional affiliations. 